\title{
Hugo Grocio: la guerra por medio del derecho
}

\section{Hugo Grotius: War through Law}

\author{
Javier Peña Echeverría ${ }^{1}$ \\ Universidad de Valladolid (España)
}

Recibido: 20-07-14

Aprobado: 30-07-14

\section{Resumen}

La posición de Grocio respecto a la guerra es considerada en este artículo como un intento de mediación entre el realismo político y el moralismo pacifista. Aunque la guerra es una consecuencia inevitable del conflicto permanente en las relaciones humanas, puede ser ajustada a los principios y reglas del derecho natural común a los hombres y del derecho de gentes resultante del consenso entre los pueblos. En consecuencia, Grocio expone las condiciones de justificación de la guerra y propone reglas de conducta en la guerra. Sin embargo, persiste una tensión insuperable entre las pretensiones normativas de la moral y el derecho, por un lado, y la lógica de la fuerza propia de la guerra, por otro.

Palabras-clave: Guerra, derecho natural, derecho de gentes, realismo político, guerra justa, ius in bello.

\begin{abstract}
Grotius's position on war is considered in this article as an attempt to mediate between political realism and moralistic pacifism. Although war is an inevitable consequence of the permanent conflict in human relations, it can be adjusted to the principles and rules of common natural law and ius gentium resulting from the consensus among peoples. Consequently, Grotius outlines the conditions for justification of war and proposes rules of conduct in war. However,
\end{abstract}

\footnotetext{
${ }^{1}$ (javierp@fyl.uva.es). Javier Peña es catedrático de Filosofía Moral y Política en la Universidad de Valladolid (España). Ha dedicado varias publicaciones a cuestiones de filosofía política contemporánea (ciudadanía, republicanismo, cosmopolitismo), pero también a la historia del pensamiento político moderno, en especial a Spinoza y a la teoría política hispánica de los siglos XVI y XVII.
} 
an insurmountable tension persists between moral and law normative claims, on one hand, and the logic of force essential to war, on the other.

Key-words: War, natural law, ius gentium, political realism, just war, ius in bello.

\section{Guerra y política: la posición de Grocio como propuesta de vía media}

Una tesis muy extendida entre los estudiosos de las relaciones internacionales diferencia tres grandes tradiciones de pensamiento en este campo. Son, en palabras del principal exponente de esta teoría, Hedley Bull,

la hobbesiana o realista, que considera la política internacional como un estado de guerra; la kantiana o universalista, que percibe en la política internacional actual una potencial comunidad de la humanidad; y la tradición grociana o internacionalista, que entiende que la política internacional tiene lugar dentro de una sociedad internacional ${ }^{2}$.

Esta doctrina no sólo viene a reconocer la importancia del pensamiento de Grocio para la teoría política y jurídica de las relaciones internacionales - algo fuera de duda para los estudiosos, más allá de la dilatada controversia respecto al papel y la ubicación del jurista holandés en la formación y desarrollo del Derecho internacional -, sino que le sitúa en un virtuoso punto medio entre realistas hobbesianos y universalistas kantianos. Los primeros, a juicio de Bull, consideran que el Estado no debe estar limitado en la persecución de sus propios intereses por restricciones morales y legales, sino a lo sumo por normas de prudencia o conveniencia. La tradición kantiana, en cambio, considera que la comunidad universal de los individuos humanos es la realidad básica de la política internacional, y su objetivo es la superación del sistema de Estados y la construcción de una sociedad cosmopolita. Los grocianos, en cambio, consideran, a diferencia de los hobbesianos, que los Estados deben atenerse también en su acción a las exigencias de la moral y el derecho; si bien, frente a los kantianos, conciben una sociedad de estados diferentes, en la que se dan relaciones de conflicto y cooperación (Cf. Bull, 2005: 76-79).

Podemos servirnos de esta clasificación como marco inicial para tratar de comprender cómo enfoca Grocio la cuestión de la guerra en su relación con la política, que es el objetivo de este artículo. La comparación de la posición de Grocio con la de realistas y pacifistas cosmopolitas nos proporciona algunas claves de interpretación de su posición respecto a la guerra. En primer lugar, conviene considerar la relación entre guerra (y en último término, política) y derecho (entendido como marco normativo referido de algún modo a principios

\footnotetext{
${ }^{2}$ Bull, 2002: 76. El propio Bull advierte de que la clasificación se debe a Martin Whight.
} 
morales). En segundo lugar, hay que atender a los supuestos antropológicos sobre los actores (sean individuos físicos o Estados) y su relación con el contexto colectivo de la acción política.

Desde luego, eso no significa aceptar la reducción de las posiciones históricamente dadas a la simplicidad de tres modelos esquemáticos. Tampoco, por lo que respecta a Grocio, podemos pasar por alto el contexto histórico e intelectual en el que se desarrolló efectivamente su pensamiento-una encrucijada entre tradición y modernidad que ayuda a comprender las vacilaciones y ambigüedades que a menudo se han observado en el pensamiento del jurista de Delft-. Menos aún cabe pasar por alto el anacronismo que supone poner como punto de comparación la posición de Kant, más de un siglo y medio posterior. $\mathrm{Ni}$, por último, se pretende ubicar a Grocio en un justo medio entre extremos de los que debería apartarse una teoría de las relaciones internacionales. No hay una solución grociana, sino más bien una búsqueda imprecisa de salidas entre esos escollos del realismo y el idealismo que amenazan a toda teoría política.

Salta a la vista que en las concepciones mencionadas de las relaciones internacionales el problema de la guerra y la paz ocupa un lugar central. Mientras para los realistas la guerra es el horizonte de la política (Schmitt dixit), el cosmopolitismo kantiano está al servicio de un proyecto de paz definitiva que excluya la guerra. En cuanto a Grocio, su obra capital, De iure belli ac pacis, a la que debe su reputación como pionero en la teoría de las relaciones internacionales, es ante todo un tratado sobre el derecho de guerra, cuestión a partir de la cual puede esbozarse una teoría de las relaciones entre los Estados, y no al revés. Puede ser útil por tanto confrontar la posición grociana con la de realistas y pacifistas cosmopolitas.

Al fin y al cabo el mismo Kant, en La paz perpetua, se refiere a Grocio, junto a otros dos teóricos del derecho natural moderno ${ }^{3}$, Pufendorf y Vattel, calificándolos irónicamente de leidige Tröster ("tristes consoladores"), en la medida en que considera que las soluciones que proponen al problema de la guerra en la Europa moderna tienen como premisa la tesis de que es insuperable la situación natural de anarquía entre Estados que no están dispuestos a renunciar a su soberanía ilimitada, y por consiguiente a la guerra en el estado de naturaleza internacional. En vano claman por una humanización de la guerra que mitigue el conflicto permanente e insuperable entre los Estados; el problema no tiene solución mientras no se establezca una verdadera comunidad jurídica que someta la violencia al derecho ${ }^{4}$.

\footnotetext{
${ }^{3}$ O, en expresión de Schmitt (2002), del ius publicum europeum.

${ }^{4}$ Respecto al juicio de Kant sobre estos autores, véase Cavallar, 2011: 70-80. Al parecer, Kant sólo habría leído a Vattel.
} 
Sea cual fuere el juicio que nos merezca la propuesta kantiana, la época de Grocio no es aún la de los proyectos de paz, sino la de la guerra interminable de los Treinta Años entre unos Estados europeos que parecen dispuestos a afirmar su propia soberanía a toda costa, sin atenerse en su conducta a restricción alguna, sino sólo a las máximas de la razón de Estado. Su propuesta puede entenderse mejor atendiendo al trasfondo teórico e histórico en el que se elabora, y a los sentimientos y consideraciones que suscita en el jurista holandés, que le llevarán a optar por una respuesta jurídica que conjugue el reconocimiento de la necesidad y la demanda de criterios normativos. En un párrafo muy citado del capítulo preliminar ("Prolegómenos") del De iure belli ac pacis podemos leer lo siguiente:

$[\ldots]$ hay entre los pueblos un derecho común que tiene vigencia para hacer la guerra y también durante ella. Muchos y muy graves motivos me inclinan a escribir sobre éste. Pues veía por todo el orbe cristiano el afán de guerra, algo tan aborrecible incluso para pueblos bárbaros. Se recurre a las armas por motivos banales e incluso nulos, y una vez tomada la decisión, se lanzan furiosamente a toda clase de crímenes, y como impulsados por una orden, sin ningún respeto del derecho divino ni del humano ${ }^{5}$.

La respuesta de Grocio puede resumirse en el intento de ajustar la guerra al derecho (e incluso, como veremos, de convertirla en un instrumento del derecho).

Adoptar un enfoque jurídico supone considerar el problema de la guerra desde una perspectiva normativa, con lo que enlaza Grocio con la tradición teológico-jurídica que se extiende desde San Agustín a la Escolástica española -cuya influencia en su pensamiento ha sido a menudo destacada. A su juicio, el derecho no es una técnica que pueda estar separada de la moral; al fin y al cabo tiene su base en el derecho natural. Sin embargo, la transformación que lleva a cabo en la concepción del derecho en un sentido individualista, en correspondencia con una visión de la sociedad y de las relaciones sociales en la que tienen prioridad los fines e intereses individuales sobre la visión comunitaria de una integración orientada al bien común, propia de la tradición aristotélica, corresponde a una antropología realista, pesimista, que da por descontada la inevitabilidad de la guerra, y reduce la moralidad a mínimos de respeto a los derechos ajenos.

Por consiguiente, Grocio descarta como extremistas propuestas pacifistas como la de Erasmo ${ }^{6}$, y admite la licitud del recurso a la guerra como medio de obtener justicia y defensa o reparación de los derechos violados. De lo que se trata es de establecer criterios jurídicos que permitan regular las condiciones

\footnotetext{
${ }^{5}$ IBP, Prol. 28. (En lo sucesivo me referiré al De iure belli ac pacis con las siglas IBP).
}

${ }^{6}$ Véase Prol. 29. 
de emprendimiento, desarrollo y consecuencias de la acción bélica. Por eso puede decirse que, mientras el cosmopolitismo jurídico siguió un camino cuyo sentido puede resumirse en el título de uno de los libros de Kelsen, La paz por medio del derecho, la propuesta de Grocio bien podría enunciarse con el análogo "La guerra por medio del derecho".

Por otra parte, respecto a la relación entre individuo y comunidad, la perspectiva de Grocio es individualista: la interacción social se concibe desde el punto de vista de un sujeto que afirma su derecho a la propia conservación en un espacio social en el que coexiste con otros sujetos movidos por intereses análogos. Grocio escribe en un momento en el que se disipa la ilusión de una comunidad universal a la vez política y religiosa -la Cristiandad-, y aún está lejos de constituirse el llamado sistema westfaliano de Estados. Se ha dicho que su teoría del derecho natural servía al propósito de justificar la actividad de los holandeses en el espacio marítimo y colonial extraeuropeo (supuestamente abierto) frente a otras potencias, y en relación con sus socios indígenas: el holandés reivindica la libertad de comercio y navegación como derecho natural (Cf. Van Ittersum, 2006: XXII). Pero no es necesario reducir el propósito de Grocio a la defensa de la razón de Estado, o del interés particular de la Compañía de las Indias Orientales, para constatar la ausencia de una auténtica comunidad humana de fines compartidos en su planteamiento, en claro contraste con el proyecto kantiano de avanzar hacia una comunidad de derecho cosmopolita en la que la guerra dejaría de ser un modo de relación habitual entre los Estados, al servicio de un equilibrio precario de intereses.

No es que falte en Grocio la conciencia de pertenencia de los individuos y las sociedades a una sociedad máximamente abarcadora, la comunidad del género humano. Es una noción que arraiga en la tradición estoica, que aparece claramente en Cicerón (e indirectamente en la idea romana del ius gentium), y que es enunciada con claridad, con alcance casi político, en Vitoria y Suárez. Pero si esta idea impulsa en ciertos momentos históricos proyectos cosmopolitas, y en la actualidad las demandas de pasar de la sociedad internacional de Estados a una sociedad mundial (Vincent, 1990: 242), en autores como Grocio queda reducida a un mínimo que hace posible la coexistencia sin fundar una auténtica comunidad ${ }^{7}$.

\section{EI Derecho y los derechos}

Así pues, la empresa del De iure belli ac pacis puede ser considerada como un intento de remitir el hecho de la guerra al marco regulador del derecho. Este proyecto se enfrenta, en primer lugar y ante todo, a la reducción de la

\footnotetext{
${ }^{7}$ Cavallar se refiere al "cosmopolitismo moral” de Grocio (2002: 139).
} 
política a mera fuerza, a la confrontación sin reglas de las potencias estatales, que comienzan a afirmarse en el espacio europeo y más allá, en las tierras descubiertas en los demás continentes y en los mares donde se desarrolla el comercio a gran escala, como poderes soberanos que no admiten superior. Esta estrategia se expresa en el realismo descarnado de las teorías maquiavélicas de la razón de Estado, que oponen política y derecho - y a fortiori guerra y derecho-; a ella se opone explícitamente Grocio, que enlaza con la tradición normativa del iusnaturalismo cristiano (aunque muy atemperada, como vamos a ver, por una antropología pesimista).

La convivencia política tiene como condición de posibilidad la regulación jurídica, incluso en su momento más conflictivo. Por eso es necesario construir un derecho de guerra. La posición de Grocio respecto a la relación entre derecho y guerra es que, frente a lo que afirman los teóricos y políticos realistas, la guerra no sólo no significa ausencia del derecho, sino que debe ajustarse a las reglas jurídicas y puede ser instrumento del fin que el derecho persigue ${ }^{8}$.

Ahora bien, la reconstrucción del derecho de guerra se enmarca en la obra de Grocio dentro de una revisión de la noción de derecho natural, y del derecho en general, que tiene profundas consecuencias para su teoría de las relaciones políticas, y en especial para las que hoy llamaríamos relaciones internacionales (incluidas las bélicas). Es posible siempre recurrir al derecho, incluso entre personas que no tienen un juez común al que apelar. Resulta obligado entonces detenerse en esta cuestión antes de abordar la del ius belli.

La reivindicación de la dimensión del derecho en la política frente al escepticismo realista, representado en los "Prolegómenos" por la figura del filósofo griego Carnéades, remite a un derecho natural que pueda ser reconocido por cualquier ser humano, como ser racional, y que por tanto pueda servir como código aplicable incluso allí donde no haya normas positivas comunes ni jurisdicción reconocida. El escéptico sostiene que el criterio de toda acción es la utilidad, y que por tanto carece de sentido la noción de justicia como imparcialidad, y por consiguiente la apelación al derecho. Sin embargo, observa Grocio, hay en los humanos un impulso natural a la asociación con sus congéneres, y sobre todo una racionalidad capaz de ajustar la conducta a normas generales que hagan posible la coexistencia tranquila y razonable ${ }^{9}$. Del mismo modo que no es necio el individuo que obedece a las leyes de su Estado, aunque eso signifique renunciar a algunas utilidades inmediatas, tampoco lo es "el pueblo que no tiene tanta estima de su propia utilidad como para despreciar el derecho común de los pueblos"10.

\footnotetext{
8 IBP, Prol., 25.

9 IBP, Prol. 5-7.

10 IBP, Prol. 18
}

Araucaria. Revista Iberoamericana de Filosofia, Política y Humanidades, año 16, n⿳⺈ 32. Segundo semestre de 2014 Pp. 69-92. ISSN 1575-6823 e-ISSN 2340-2199 doi: 10.12795/araucaria.2014.i32.04 
La apelación al deseo de sociedad y a la capacidad de establecer normas generales gracias a la palabra podría llevar a pensar al lector desprevenido que Grocio mantiene la perspectiva aristotélica generalizada entre los autores de la Segunda Escolástica. Pero no es así. Mientras Aristóteles piensa en un individuo integrado en un organismo social del que recibe su identidad y en el que sus actividades tienen sentido, en Grocio opera la idea estoica (ciceroniana) de la comunidad del género humano, pero que aquí se hace extremadamente tenue; se trata sólo de un espacio de coexistencia de derechos. La sociabilidad "es para Grocio simplemente el respeto de los derechos de otro, concebidos subjetivamente, de manera que [...] un mínimo de vida social sea posible" (Haakonsen, 1985, 17). Grocio representa una concepción de la sociedad civil y de la sociedad internacional basada esencialmente en los derechos y limitada a ellos (Kingsbury y Roberts, 1990: 13).

Estos presupuestos antropológicos son congruentes con la transformación del concepto de derecho que encontramos en Grocio. Baste recordar - sin entrar aquí en el debate sobre los orígenes y novedad de la aportación de Grocio - que mientras tradicionalmente el término ius se refiere primordialmente a lo que es conforme al derecho (entendido éste en sentido objetivo) -, en De iure belli ac pacis aparece una acepción del término en la que pasa a ser algo subjetivo, una facultad que una persona tiene: "una cualidad moral de la persona, en virtud de la cual puede hacer o tener algo lícitamente"11. Esta facultad de disposición de un sujeto sobre lo que es suyo, sea el poder sobre sí mismo o sobre otras personas, su propiedad, y la facultad de exigir lo que le es debido (crédito), es su derecho ${ }^{12}$.

Los estudiosos observan cómo esta definición del derecho fundada en el derecho subjetivo introduce una perspectiva individualista, que afecta en primer lugar a la concepción del derecho natural, e indirectamente al conjunto de la teoría jurídica y política del autor. El derecho es el conjunto de los derechos individuales, derechos que concurren en el espacio social, escenario de coexistencia, de eventual colaboración, pero sobre todo de competencia y potencial conflicto, por lo que las expectativas de la vida social se reducen a la coexistencia pacífica. Lejos queda la representación aristotélica de la sociedad política como comunidad orientada al bien común (Por ello se ha visto en el individualismo grociano una anticipación de lo que será la concepción típicamente liberal de la vida social).

Ciertamente, el derecho natural dibuja un orden moral objetivo al que han de ajustarse los impulsos y aspiraciones del individuo, que tienen como base el deseo de autopreservación. Grocio lo define como el "dictado de la recta razón", que nos muestra cómo las acciones son correctas o no, "según

${ }^{11} I B P, \mathrm{I}, 1,4$.

$12 I B P, \mathrm{I}, 1,5$.

Araucaria. Revista Iberoamericana de Filosofía, Política y Humanidades, año 16, n 32. Segundo semestre de 2014. Pp. 69-92. ISSN 1575-6823 e-ISSN 2340-2199 doi: 10.12795/araucaria.2014.i32.04 
su conformidad o disconformidad con la misma naturaleza racional y social", y en consecuencia han sido prescritas o prohibidas por Dios, el autor de la naturaleza ${ }^{13}$. Se trata de un orden de normas sustraído a la arbitrariedad e inconstancia de la voluntad humana (Haggenmacher, 1983: 517). Pero si nos preguntamos cuál es su contenido, nos encontramos únicamente con preceptos negativos, que atañen al respeto de los derechos ajenos: se trata de abstenerse de lo ajeno, restituir lo que se tenga o se haya tomado ilegítimamente, reparar el daño causado, mantener la palabra dada (cumplir las promesas) ${ }^{14}$. Se trata, como observa Tuck, de una visión "extremadamente mínima de la vida moral" (1999: 86): cada uno puede perseguir sus propios intereses, sin más obligación que la de no interferir en el ámbito de derechos de los demás.

Esta concepción minimalista se muestra también en el tratamiento del tema de la justicia. El derecho subjetivo en sentido estricto (facultas), el derecho perfecto, se refiere únicamente a la justicia, que es netamente diferenciada de las demás virtudes (generosidad, misericordia, prudencia). A su vez, la justicia propiamente dicha es la que Aristóteles llama justicia correctiva, la conmutativa, mientras que la justicia distributiva queda relegada al ámbito de los derechos imperfectos, no estrictamente tales ${ }^{15}$. Esto es, la concepción aristotélica de un bien común de la comunidad desaparece junto con la idea de una justicia universal propia de la sociedad; queda sólo "el mantenimiento o la mera compatibilidad en la persecución de pretensiones de derechos individuales" (Haakonsen, 1985: 253). No se puede decir que Grocio venga a establecer aquí la separación entre derecho y moral, que aún habrá de esperar a Thomasius, pero la distinción entre derechos perfectos e imperfectos representa un paso importante en ese sentido ${ }^{16}$.

Dada la nueva concepción subjetivista del derecho natural, podemos determinar su contenido en términos de derechos naturales de los individuos: el derecho a la defensa propia, el derecho de propiedad, el derecho a la restitución de las deudas, así como el derecho a castigar la violación de esos otros derechos; una especie de "derecho de segundo orden", según observa Haakonsen (1985: 242), que tiene un carácter correctivo, de justicia compensatoria.

Este derecho de castigo merece capítulo aparte, porque en último término sirve de fundamento para justificar la decisión de emprender la guerra. Ya hemos visto que Grocio lo concibe como un derecho natural del individuo, anterior al

${ }^{13} I B P, I, 1,10,1$. Prescindo aquí de la controversia sobre el carácter más o menos intelectualista o voluntarista de la concepción iusnaturalista de Grocio, así como sobre el alcance y límites de la secularización del derecho natural en este autor.

14 IBP, Prol. 8.

${ }^{15}$ IBP I, 1, 4-8. Véase igualmente II, 22, 16, donde el autor deja claro que sólo hay un deber estricto de hacer algo allí donde alguien tiene un derecho correspondiente; la existencia de un deber moral no es suficiente.

${ }^{16}$ Es bien conocida la equiparación de Grocio con Hobbes que hace Rousseau: "La verdad es que sus principios son exactamente semejantes, sólo difieren en las expresiones” (Rousseau, 1990: 623). 
establecimiento de los Estados, a diferencia de la tradición escolástica, la cual lo atribuye a la comunidad política como tal. Sólo corresponde al magistrado, una vez creado el Estado, por cesión contractual del derecho originario de los individuos.

El derecho natural a castigar introduce la posibilidad de imponer sanciones incluso allí donde no existe una legalidad positiva, como sucede en el estado de naturaleza o en la esfera internacional. La comunidad original de los hombres sigue existiendo, al menos virtualmente, en cualquier caso, por lo que es lógico que "cuantas veces fallen las garantías establecidas por la sociedad civil, sean las reglas naturales las que se apliquen” (Haggenmacher, 1983: 228).

La existencia de un derecho natural a castigar la incorpora ya Grocio en el De iure praedae, donde el holandés, como jurista al servicio de la Compañía de las Indias Orientales, justifica la captura del navío portugués Santa Catarina por barcos holandeses de la citada compañía como ejercicio del derecho que asiste a los particulares frente a quienes tratan de impedir su derecho natural a viajar y comerciar en el mar abierto, el cual no puede ser reclamado por nadie como su propiedad privada, sino que es res communis de la Humanidad.

Este derecho a castigar no alcanza sólo a las ofensas o violaciones de los propios derechos, sino que se extiende a las cometidas contra los derechos de cualquier otro, allí donde no hay una jurisdicción reconocida. Con una argumentación idéntica a la que Locke empleará en el Segundo Tratado sobre el gobierno civil $^{17}$, el jurista holandés sostiene que la injuria inferida a cada hombre afecta a todos, en la medida en que supone una violación del derecho que naturalmente rige a la comunidad de la humanidad, y por tanto todos y cada uno tienen derecho a castigarla. De esta manera puede hacerse efectivo el orden legal natural, siquiera imperfectamente, incluso en ausencia de una autoridad política común.

Este derecho se aplica igualmente a los Estados, según la analogía que los ve como individuos independientes en la esfera internacional, carente así mismo de una autoridad política superior ${ }^{18}$. Ello da pie a una interpretación amplia de ese derecho que vendría a justificar la moderna "intervención humanitaria", al menos en casos extremos (como el canibalismo o la piratería) pero también el recurso a la fuerza en defensa de la civilización europea y su interpretación de los derechos:

Debemos saber también que los reyes, y aquellos que están investidos de un poder igual al de los reyes, tienen derecho a exigir castigos, no sólo por las injurias cometidas contra ellos mismos o sus súbditos, sino igualmente contra aquellos que no son de su particular incumbencia, pero las cuales violan desmesuradamente el derecho natural o de gentes en cualquier persona. Pues la

${ }^{17}$ Cf. $\S \S 7,9$. Llaman la atención sobre esta coincidencia Tuck (1999: 82) y Straumann (2006: 7).

${ }^{18} \mathrm{Cf} . \mathrm{IBP}, \mathrm{II}, 15,12,1$. 
libertad para servir los intereses de la sociedad humana a través de las penas, que, como hemos dicho, reside originalmente en los individuos, ahora, después del establecimiento de los estados y tribunales de justicia está en manos de las autoridades supremas, no, hablando en propiedad, en tanto que gobiernan sobre otros, sino en tanto que no están ellos mismos sujetos a nadie ${ }^{19}$.

Hay que reconocer que el mismo Grocio era consciente del riesgo de que tales intervenciones sean un pretexto al servicio de la ambición y la avaricia de los intervinientes. No obstante, el mal uso que se pueda hacer de la injerencia no invalida el deber general de prestar ayuda a quienes son oprimidos por un tirano (IBP, II, 25, 8, 4). Los soberanos tienen una responsabilidad subsidiaria por la humanidad en su conjunto (Vincent, 1990: 247).

Cabría pensar que este derecho a castigar la violación de derechos habría de tener también una potencial aplicación en el orden interno, puesto que podría ser reivindicado por los súbditos frente a la violación de sus derechos naturales por parte del gobernante. Así lo hará Locke, que funda en él el derecho de resistencia frente al poder constituido. En cambio, Grocio, aunque admite el derecho de resistir pasivamente a las órdenes contrarias al derecho natural y a los mandatos divinos (IBP I, 4, 1, 3), excluye el derecho de resistencia activa (IBP I, 4, 2, 1), argumentando que el objetivo de la paz pública y el orden de la sociedad, que está por encima de todo, resultaría imposible si cada cual invocase un derecho de resistencia, porque se disolvería la ciudad. No obstante, el autor admite ciertas excepciones, referidas a aquellos casos en los que el rey abdica o aliena de hecho su autoridad, o se comporta como enemigo del pueblo ${ }^{20}$, o se ha establecido expresamente de antemano una limitación a su arbitrio (IBP I, 4, 8 -13). Parece que lo que se rechaza es la rebelión de individuos o grupos contra el poder político establecido institucionalmente, más que el derecho del pueblo como tal a velar por su conservación. (Lo cual no impide que Grocio se muestre más bien escéptico respecto a la hipótesis de la soberanía popular, y defienda la superioridad del rey respecto al pueblo; véase IBP, I, 3, 8-14).

En De iure praedae Grocio había sostenido que el derecho a la propia preservación nos autoriza a perseguir nuestros intereses sin necesidad de contar con el permiso de ninguna autoridad ${ }^{21}$. Ello era congruente con la pretensión de justificar el derecho de los navíos holandeses a navegar y establecer relaciones comerciales en las Indias orientales y occidentales, al margen de la asignación establecida por las bulas papales. Sin embargo, esta perspectiva radicalmente individualista cede en el De iure belli ac pacis ante el protagonismo del sujeto colectivo estatal, concebido igualmente como titular soberano de derechos. ( $\mathrm{Si}$

\footnotetext{
${ }^{19}$ IBP, II, 20, 40, 4. Véase también II, 25, 8, 3.

${ }^{20}$ Lo que abriría de nuevo un portillo para justificar el derecho de resistencia por la vía seguida por Locke.

${ }^{21} \mathrm{Al}$ menos en estado de naturaleza: véase De iure praedae, I, 12.
} 
bien el autor no llega realmente a concebir la noción de soberanía estatal en abstracto; es a la soberanía del gobernante dentro del Estado a la que atiende; véase al respecto Haggenmacher, 1983: 539-540). Si los derechos del individuo son anteriores a cualquier autoridad, la ambición humana y la corrupción hacen necesaria la autoridad civil para garantizar los derechos naturales. Por eso los individuos renuncian a su derechos originarios y a su derecho a castigar a otros en caso de que transgredan sus derechos (IBP, I, 3, 7, 1).

Es más: sobre la base de la justificación de la esclavitud como cesión absoluta de derechos -lo que supone, obsérvese, la mercantilización de los derechos como posesiones con las que se puede negociar-, Grocio llega a sostener que si un individuo puede hacerse esclavo voluntariamente, lo mismo puede hacer un pueblo (II, 24, 6, 2). Como advierte Vincent (1990: 246), difícilmente puede ser considerado Grocio como un defensor de los derechos humanos.

Lo que vale para los individuos en sus relaciones mutuas vale igualmente para el Estado en su relación con otros colectivos equivalentes. Gobernantes y Estados están igualmente sujetos a las reglas del derecho natural, válido para toda la Humanidad. Los Estados han de ser considerados como individuos, cada uno de los cuales persigue su propio interés y se afana por su supervivencia. Ambos pueden usar la violencia del mismo modo y para los mismos fines. Ahora bien, como partícipes de la comunidad del género humano, sus prácticas han de atenerse al marco básico del derecho natural.

No obstante, Grocio deja espacio en la regulación de la coexistencia de individuos y Estados a una variedad de tipos de derecho. Distingue entre derecho natural y derecho voluntario, y a su vez éste se divide en divino y humano. Por último, el derecho voluntario humano se bifurca en derecho civil y derecho de gentes (IBP, I, 1, 14). Como es obvio, es este último, el conjunto de reglas relativas a las relaciones fuera de los límites de la ciudad, el que tiene mayor importancia en lo que se refiere a la guerra.

En efecto, Grocio concibe el derecho de gentes, en contraposición al natural, como un derecho "voluntario", de creación humana, surgido del consenso de los pueblos y manifiesto en la práctica de los Estados ${ }^{22}$. No obstante, no se trata de un derecho positivo, sino de un derecho con fundamento positivo (el cual, sin embargo, no es precisado) ${ }^{23}$. El mismo Grocio distinguirá a su vez entre un derecho de gentes en sentido impropio -las costumbres

${ }^{22}$ IBP I, 1, 14: "Quod gentium omnium aut multarum voluntate vim obligandi accepit".

${ }^{23}$ Subsiste la cuestión del origen de este consenso. Algunos entienden que se funda en el hecho del acuerdo alcanzado históricamente por los asociados, o en el acogimiento o imitación paulatina de costumbres ajenas, mientras que otros, como Lauterpacht, piensan que se alcanza el consenso porque subyacen al acuerdo una naturaleza y un derecho "natural" compartidos. Al fin y al cabo, la comunidad virtual de los Estados se basa en la comunidad natural de los hombres.

En todo caso, omito aquí la referencia a la extensa historia de las interpretaciones del derecho de gentes, siempre oscilantes entre el acercamiento al derecho natural o el derecho positivo. 
generalizadas entre los diversos pueblos- $\mathrm{y}$ en sentido estricto - los acuerdos de las naciones en su relación recíproca-; no es posible identificar sin más con el derecho internacional en su sentido actual un derecho que no se refiere sólo a los Estados, sino también a los individuos.

Aunque en principio debería estar clara la relación jerárquica entre el derecho natural y el de gentes ${ }^{24}$, los intérpretes coinciden en señalar cómo Grocio tiene un proceder ecléctico, que amalgama fundamentos de derecho en respuesta a los variados problemas que considera, sin dejar claro cuál tiene prioridad en caso de conflicto; en particular, si el derecho natural o el derecho de gentes. Hay cierta confusión respecto a cuál es el derecho al que se remite el autor en cada caso; particularmente, en lo que se refiere a la justicia de la guerra (Draper, 1990: 93). Como vamos a ver, el recurso indiscriminado a diversas fuentes favorece el logro de respuestas más flexibles y adaptadas al caso a los dramáticos conflictos morales que plantea la guerra.

\section{Guerra, derecho y justicia}

Como enuncia claramente su título, De iure belli ac pacis es sobre todo un tratado sobre el ius belli, si bien la exposición sobre el derecho de guerra se construye sobre la de los fundamentos del derecho (natural y de gentes), que proporcionan la base de justificación para la regulación de esas situaciones de conflicto extremo en las que no cabe el recurso a una norma positiva común. Esta estrategia metódica, junto con el cúmulo de referencias a autoridades y ejemplos históricos de los que Grocio se sirve (que abruman al lector que no comparta la sensibilidad barroca de los lectores de su época), no deben desviarnos del propósito central del autor.

La premisa básica o punto de partida es que la guerra es un fenómeno inevitable, que hunde sus raíces en la condición humana. Los presupuestos antropológicos y la ontología social de Grocio, a los que se ha hecho referencia más arriba, hacen impensable la hipótesis irenista de un mundo definitivamente pacificado.

Pero que la guerra sea un estado de violencia no significa que sea por completo ajena o incompatible con el derecho. Al fin y al cabo, la naturaleza ha dotado a todo animal de fuerza y de un instinto agresivo para defenderse de sus enemigos, y "la recta razón y la naturaleza de la sociedad [...] no prohíben toda violencia, sino sólo aquella que repugna a la sociedad, es decir que atenta

${ }^{24}$ Lauterpacht, 1946: 21: "el significado del derecho natural en el tratado es que es la fuente omnipresente para suplementar el derecho de gentes voluntario, para juzgar su adecuación a la luz de la ética y de la razón, y para hacer al lector consciente del hecho de que la voluntad de los Estados no puede ser exclusivamente, o incluso en última instancia, la fuente decisiva del derecho internacional". 
contra los derechos de otro" ${ }^{25}$. Tampoco desaprueba la guerra el derecho de gentes voluntario, como vemos en la historia, las leyes y las costumbres de todos los pueblos (véase IBP I, 2, 4) ${ }^{26}$.

Acepta, por tanto, Grocio la guerra como un fenómeno reconocido por el derecho, sin que ello suponga admitir el recurso sin restricción a la guerra, sino que reclama fundamento legal para emprenderla (Draper, 1990: 200). Se aparta por tanto de la posición realista de Hobbes, para quien guerra y derecho se excluyen: en la guerra sólo cuenta la relación de fuerzas entre los contendientes ${ }^{27}$. (También Kant piensa que el estado natural de relaciones entre los Estados es un estado de guerra, contrario al derecho; por eso cree que el intento de Grocio y los demás exponentes del Ius publicum europeum no es más que un triste remedo de solución).

La alternativa básica, por tanto, era optar por la concepción del realismo político, para la que las relaciones internacionales, en un espacio sin autoridad o ley reconocida, consisten en una confrontación de fuerzas, o bien por lo que se conocerá más adelante como concepción grociana: una sociedad de Estados en la que la guerra es sólo un acontecimiento social posible (Donelan, 1983: 233). Otra posible solución, la de un mundo unificado bajo una autoridad reconocida universalmente, está descartada en la época de Grocio ${ }^{28}$.

Como apunta Nabulsi (1999: 22): "Su meta no fue determinar si podría haber reglas que gobernasen la guerra y la paz, sino definir cuáles eran. Al hacerlo creó un sistema de derecho que podría ofrecer derechos bilaterales a ambos beligerantes en la guerra, un principio adicional al tradicional ius ad bellum".

La guerra es el medio a través del cual los derechos de los Estados se hacen cumplir contra aquellos que los violan:

Lejos de la verdad lo que algunos piensan, que todo derecho cesa ante la guerra; más bien, no debe emprenderse la guerra sino para conseguir el derecho y, una vez iniciada ésta, debe llevarse según la forma del derecho y de buen $\mathrm{fe}^{29}$

Aceptada la guerra como momento de la vida social sujeto al derecho, se abre camino una teoría judicial de la guerra, que puede ser normalizada como proceso. Allí donde no es posible recurrir a la sentencia judicial ordinaria, la guerra sirve como procedimiento alternativo ${ }^{30}$. En ausencia de las condiciones

\footnotetext{
${ }^{25}$ Ius alienum tollit. IBP, I, 2, 1, 4.

${ }^{26} \mathrm{Ni}$ está absolutamente prohibida la guerra por la doctrina evangélica (a lege Christi. IBP, I, 2, 7).

27 También Spinoza considera que los Estados se relacionan según su potencia en el estado de naturaleza internacional. Véase Tratado Político, III, 11-16.

${ }^{28}$ Grocio rechaza la idea de un Imperio universal, inverosímil, porque necesitaría el reconocimiento de los más diversos pueblos de la Tierra, e inmanejable por su vastedad. Cf. IBP, II, 22, 13.

${ }^{29}$ IBP, Prol. 25.

${ }^{30} \mathrm{IBP}, \mathrm{II}, 1,2$, 1: Ubi iudicia deficiunt incipit bellum. "La juridificación grociana de la guerra 
de desempeño de la justicia propias de la sociedad civil, los Estados contendientes actúan como jueces, juzgando, pronunciando la sentencia - en forma de declaración de guerra - y condenando a los agresores injustos como criminales $^{31}$.

La concepción de la guerra como un acto judicial es muy antigua. Arranca, según Donelan, de Cicerón y de la Roma imperial. Desde San Agustín es vista como un acto de justicia vindicativa. "La imagen judicial sobrevivió y brilló de nuevo en los teólogos del siglo XVI que escribieron sobre política, principalmente Vitoria y Suárez; y es la imagen más plenamente desarrollada de la guerra en su sucesor, Grocio" (Donelan, 1983: 234) 32. La república desempeña la autoridad "para castigar las injurias cometidas contra ella y sus súbditos y para exigir reparación por ellas"-escribe Vitoria ${ }^{33}$.

Ahora bien, la concepción de la guerra como parte de un proceso contiene una distinción implícita entre guerras justas e injustas: la guerra no es un despliegue arbitrario de poder, sino que debe ser un instrumento de la justicia. Importa tener en cuenta que desde la perspectiva de los teólogos y juristas lo que importa sobre todo al pensar en la guerra es la calificación moral y jurídica de las acciones. Puesto que la guerra supone siempre ejercicio de la violencia contra las personas y sus bienes, así como la utilización de medios y estratagemas aparentemente contrarios al mandato evangélico e incluso a los preceptos del derecho natural, la reflexión sobre la guerra es, hasta Grocio, una teoría de la guerra justa. (Falta en cambio, como se dirá más adelante, una normativa neutralizada sobre la actividad bélica en sí misma).

En su erudito estudio sobre la doctrina de la guerra justa en Grocio, Haggenmacher (1983) sostiene que esta doctrina nace en lo esencial en los siglos XII y XIII. Como en tantas otra cosas, es Tomás de Aquino quien presenta por primera vez una exposición sistemática y autónoma sobre la guerra y su justificación moral ${ }^{34}$. Pero la controversia sobre la cuestión alcanza su mayor desarrollo en el siglo XVI. Por una parte, Erasmo y Lutero actúan como catalizadores del debate teológico, que fue desarrollado más tarde por los teólogos y juristas de la Segunda Escolástica, a partir de la relección de Vitoria

permite por consiguiente justificar la guerra sólo en tanto que aparece como sustituto de una justicia que no se puede ejercer" (Zarka, 1998: 179).

${ }^{31} I B P$, II, 1, 16: “...en una guerra privada el derecho de defensa viene a ser sólo momentáneo, y cesa tan pronto como uno puede apelar a un juez; mientras que en una guerra pública, que surge sólo entre quienes no reconocen un juez común, o cuando el ejercicio de la justicia está interrumpido, el derecho de defensa tiene continuidad, y se mantiene perpetuamente respecto a las injurias recientes y daños recibidos".

${ }^{32}$ También Haggenmacher señala que es en los escolásticos del siglo XVI donde la apertura de la guerra se aproxima más estrechamente a una sentencia judicial, al tiempo que advierte de la intención restrictiva de esta equiparación: "la idea de la sentencia apunta a mantener la guerra en sus justos límites, más que a contener sus excesos" (Haggenmacher, 1983: 245).

${ }^{33}$ De iure belli, §5.

${ }^{34}$ Summa Theologica, II-II, q. 40, a. 1. 
De iure belli. El dominico expone, siguiendo a Santo Tomás, los requisitos de la guerra justa: que sea declarada y dirigida por una autoridad legítima, que tenga como fin reparar o castigar una injusticia cometida por el enemigo, y que sea recta la intención de los combatientes (restablecer la paz y la seguridad).

El tratado de Grocio sigue inscrito en esta tradición doctrinal. "Vio la idea de la "guerra justa" primariamente en términos jurídicos y morales, esto es, como la respuesta legítima a la amenaza o violación efectiva de un derecho reconocido por la ley, o al rechazo a la reparación por tal violación" (Draper, 1990: 192). En buena medida, la ambigüedad y el eclecticismo de sus respuestas se deben a que no renuncia a la justificación de acciones que parecen alejadas de la doctrina cristiana, pero que son por otra parte habituales e incluso aparentemente necesarias en la vida real de las sociedades europeas.

El Estado tiene derecho a castigar a través de la guerra ${ }^{35}$. Como ya se ha indicado, ese derecho al castigo lo tiene todo individuo en el estado de naturaleza, puesto que la competencia originaria (belli gerendi potestas) corresponde a la sociedad del género humano, que comparte una naturaleza común, de la que forma parte. Pero una vez cedida la autoridad al gobernante, sólo éste retiene la facultad punitiva (Cf. IBP, II, 20, 7-9). Ahora bien, para ejercerla es necesaria una causa justa.

Es el derecho natural el que determina las causas justas de guerra. Los principios de la recta razón nos indican qué es lo justo, y por tanto lo que no nos está permitido hacer. Sólo se puede hacer la guerra para hacer valer los derechos frente a cualquier infracción: en realidad, la única causa justa de guerra es la violación de derechos (iniuria) ${ }^{36}$. Lo mismo había dicho Vitoria: la injuria recibida es la única causa legítima de guerra ${ }^{37}$. El problema es que el concepto de iniuria se puede aplicar muy holgadamente, tanto respecto a las causas como a los responsables.

Las causas justas basadas en el derecho natural y el derecho de gentes son (IBP II, 1, 2, 2): a) La defensa contra la injuria efectiva o amenaza del enemigo ${ }^{38}$; b) la recuperación de lo que le es debido al Estado ofendido; c) infligir castigo al Estado que haya obrado injustamente. La guerra no puede ser justificada por la utilidad del Estado o el príncipe, o por su gloria personal. Distingue entre guerras justificables y aquellas en que el derecho es mero pretexto (Cf. IBP, II, $22,3,1)$. Grocio está lejos aún de la concepción de la guerra como instrumento

${ }^{35}$ Téngase en cuenta que esto no significa que el fin último de la guerra sea el castigo.

${ }^{36}$ IBP II, 1,1, 4: "Causa iusta belli suscipiendi nulla esse alia potest, nisi iniuria". Straumann afirma que el recurso a la guerra está concebido según el modelo de las acciones penales del derecho romano (Cf. Straumann, 2006:3).

${ }_{37}$ Vitoria, De iure belli, § 13. Son motivos lícitos de guerra, según Vitoria: la defensa del bien público; la recuperación de bienes (o su equivalente en dinero); el resarcimiento con bienes del enemigo de gastos de guerra y daños ocasionados por él; las medidas encaminadas a garantizar la paz futura; el castigo de los culpables.

${ }^{38}$ Pero no se justifica la agresión preventiva. Cf. IBP II, 1, 17; II, 22, 5, 1. 
de la política exterior, tal como será concebida en el siglo siguiente.

Ahora bien, la doctrina de la guerra justa se enfrenta al problema de cómo determinar cuál de los contendientes tiene de su lado la justicia. La doctrina escolástica sostenía que no es posible que la guerra sea justa por las dos partes, puesto que esto llevaría al absurdo de imposibilitar la guerra (que sería injusta contra el enemigo que actúa justamente). No obstante, Vitoria concede que la guerra puede estar subjetivamente justificada para los dos contendientes, en la medida en que alguno de ellos ignore de buena fe cuál es la causa justa ${ }^{39}$.

Pero además, la progresiva transformación del mapa político europeo en un conjunto de Estados soberanos plantea el problema de quién tiene capacidad de arbitrar una decisión en caso de conflicto sobre la justicia de la guerra. Cuando los contendientes son príncipes soberanos no hay en la práctica otra autoridad por encima de las partes que pueda determinar si la guerra emprendida es justa, y aquéllos se hallan en la tesitura de decidir por sí mismos, unilateralmente, quién tiene el derecho de su parte. Cada uno es juez y parte en el litigio; se excluye un hipotético juicio colectivo de la comunidad de Estados. El único criterio aplicable en la práctica para legitimar la guerra es que haya sido declarada por la autoridad del príncipe.

Paradójicamente, la doctrina de la guerra justa, que en principio parecía subordinar la voluntad del Estado (en realidad, del gobernante) a principios morales, puede llevar la guerra a extremos de inhumanidad. Si es cada Estado quien decide cuándo sus derechos o intereses legítimos son violados, y cuándo la injuria merece castigo, es posible que los gobernantes, al considerarse intérpretes de la justicia, se muestren más despiadados con los soldados enemigos, vistos como criminales que deben ser castigados por sus culpas, que si los considerasen como adversarios en pie de igualdad. Como vamos a ver, es a partir de esta paradoja como "se desarrolló la presunción práctica de que si ambas partes creían en la justicia de su causa, eran acreedoras al beneficio de la duda" (Draper, 1990: 183).

También Grocio rechaza que la guerra pueda ser objetivamente justa por ambas partes. Sin embargo, puede ser subjetivamente justa la conducta de ambos contendientes, en tanto que ninguno de ellos sea consciente de obrar injustamente. Uno y otro pueden recurrir de buena fe a la guerra para dar solución a un litigio irresoluble por otra vía, lo que supone que ambas partes tendrían título válido para ser tratadas como participantes en una guerra justa, con los efectos consiguientes. (Bien es verdad que Grocio advierte que es poco probable que realmente se produzca esa hipótesis en el caso de la guerra, que por su importancia requeriría una convicción evidente de su justicia: cf. IBP, II, $23,13,4)$. En todo caso, la cuestión le sirve al autor del tratado para plantear que la guerra puede ser también justa por una y otra parte en el sentido de que se procede a ella conforme a las condiciones formales adecuadas, sea o no justa

\footnotetext{
${ }^{39}$ Vitoria, De iure belli, $\S 32$.
} 
materialmente, del mismo modo que una sentencia incorrecta o una posesión injusta tienen sin embargo efectos jurídicos (IBP, II, 23, 13, 5).

Grocio recuerda que esto es reconocido por el derecho de gentes. Teniendo en cuenta que por "lícito" puede ser entendido, no sólo lo que es válido en conciencia o ante Dios, sino lo que no es castigado por las leyes humanas, afirma el jurista holandés que "en ese sentido es lícito para un enemigo dañar a otro en su persona y sus bienes. Y no sólo para aquel que hace la guerra por una causa justa, y la hace dentro de los límites prescritos por el derecho natural (...), sino por las dos partes y sin distinción" (IBP, III, 4,3$)^{40}$.

Por este camino se abre paso "una toma de distancia - al menos relativa de Grocio respecto a la problemática tradicional de la guerra justa: el derecho de guerra ya no está arraigado en su origen en una cuestión teológica, y resulta susceptible de reorientación hacia una problemática de la juridificación consensual de la guerra" (Zarka, 1998: 176).

En efecto, la imposibilidad de una aplicación realista de la doctrina de la guerra justa da pie a una segunda imagen de la guerra como un duelo entre partes que tienen igual status y defienden sus pretensiones; no se trata ya de la aplicación de un castigo al agresor injusto (Donelan, 1983: 237), sino de un conflicto bilateral entre partes con igual título para litigar. Podría decirse que pasamos de la perspectiva del derecho penal a la del derecho civil (Haggenmacher, 1983: 404), a la vez que de la justicia sustancial a la corrección procedimental. "Justo" pasa a ser sinónimo de conforme a los requisitos formales establecidos por acuerdo de las partes.

Al evitar la criminalización del enemigo por ambas partes, consideradas jurídicamente como iguales, parece a primera vista más factible evitar los excesos de la guerra, y establecer ciertas restricciones, puesto que lo que hagamos en la práctica de la guerra pueden hacérnoslo a nosotros. Pero es dudoso que así sea. Donelan observa (1983: 238) cómo el propio Grocio describe de qué modo, bajo el derecho de gentes del mundo clásico, se mató sin discriminación a soldados, civiles, mujeres y niños, se masacró a prisioneros, se negó cuartel a quienes se rendían, igualmente y sin piedad (IBP III, 5-12). Puesto que nadie puede denunciar injusticia en la conducta del otro, aquel que sea más fuerte entre los contendientes, igualados jurídicamente, puede imponer sus normas: en la práctica, la fuerza establecería el derecho, como ya observó Rousseau ${ }^{41}$. Todo acuerdo y regulación sobre la guerra serán precarios y asimétricos.

No obstante, esta concepción de la guerra y su justificación dará paso a un marco jurídico regulador del curso y los hechos de la guerra, lo que se denomina comúnmente ius in bello.

\footnotetext{
${ }^{40}$ Grocio sostiene que, según el derecho de gentes, quien en una guerra solemne (esto es, declarada por la autoridad pública), la haga o no por una causa justa, se apropia de lo que toma al enemigo, ha de ser considerado a efectos jurídicos auténtico propietario de esos bienes (IBP, III, 6, 2).

${ }^{41}$ Del contrato social, I, 3.
} 


\title{
El ius in bello: restricción y moderación en la guerra
}

Aunque el concepto de ius belli comprende todos los aspectos de la guerra, podemos encontrar en el propio Grocio la distinción entre el derecho a la guerra y el derecho en la guerra, "un derecho común que tiene vigencia para hacer la guerra y también durante ella (ad bella et in bellis)" ${ }^{\prime 42}$. Pero esto no significa que estuviera presente en sus escritos la noción de ius in bello tal como la entendemos hoy, aunque las ideas de Grocio jugaran un papel crucial en la construcción de la noción moderna de ius in bello (Nabulsi, 1999: 25).

Por ius in bello se entiende actualmente un cuerpo de normas que rigen la conducta en las hostilidades, las cuales se aplican por igual a todos los beligerantes, sea cual fuere su posición en lo referente a la licitud de la guerra ${ }^{43}$.

El tratadista suizo Vattel es el primero en servirse de la noción (que no del término) de ius in bello en este sentido. Afirma que la guerra no puede ser justa por ambas partes, por razones lógicas: ambas no pueden estar a la vez en lo cierto acerca de la verdad de una proposición (Vattel, 1758, vol. 2, libro III, cap. $3^{\circ}, \S 39$ ). Pero sí pueden ambos contendientes obrar de buena fe, y en una causa dudosa es incierto de qué lado se encuentra el derecho. Por lo que, puesto que las naciones han de ser consideradas iguales e independientes, en tal caso "las armas de las dos partes que se hacen la guerra deben pasar igualmente por legítimas, al menos en cuanto a los efectos exteriores, y hasta que se decida la causa" (Vattel, 1758, loc. cit., §40).

Aparece así la noción de la guerra legítima formalmente, "guerre en les formes" (iustum bellum), caracterizada por el cumplimiento de ciertas formalidades, como la declaración solemne por un soberano y la demanda de una justa satisfacción, el status reconocido a los súbditos del enemigo que se halle en el propio país en el momento de la declaración, etc.:

\begin{abstract}
Así, cuando una nación, o un soberano, ha declarado la guerra a otro soberano, a causa de una diferencia que ha surgido entre ellos, esa guerra es lo que se denomina entre las naciones una guerra legítima y en forma (en les formes); como veremos más en detalle, los efectos son los mismos por una y otra parte, según el derecho de gentes voluntario, independientemente de la justicia de la causa ${ }^{44}$.
\end{abstract}

Vattel se cuida de advertir, como lo había hecho Grocio, de que el derecho de gentes no basta para justificar moralmente la conducta y tranquilizar la

${ }^{42} I B P$, Prol., 28. Por su parte, Vitoria había distinguido en su opúsculo sobre el derecho de guerra entre motivos válidos para hacer la guerra $(\S \S 15$ y ss.) y límites de lo permitido en la guerra justa ( $\S 34$ y ss.)

${ }_{43}$ Kolb (1997:1) hace notar que, pese a la apariencia de antigüedad que les da el latín, las expresiones ius ad bellum y ius in bello se acuñaron en la época de la Sociedad de Naciones, y apenas se usaron en la doctrina jurídica hasta finales de la década de 1940.

${ }^{44}$ Vattel, 1758, vol. II, libro III, cap. $4^{\circ}, \S 68$. 
conciencia de los actores, sino que se limita a producir el efecto exterior de derecho, con la consiguiente impunidad ante los hombres. Pero en el terreno jurídico "la guerra en forma debe ser considerada en cuanto a sus efectos como justa por una y otra parte" (Vattel, 1758, vol. 2º III, 12, §190), y ambos contendientes son equiparados en derechos: todo lo que le esté permitido a uno le está permitido al otro $(\$ 191)$.

En consecuencia, el foco se desplaza desde la justicia material a las cualidades formales del enfrentamiento (calidad pública de los contendientes, declaración de guerra ajustada a los procedimientos, etc.). "La guerra se ha convertido aquí en un "estado", una situación de hecho considerada por sí misma y regulada en consecuencia, sin tener en cuenta sus orígenes ni los fines concretos de las partes. La cesura entre ius ad bellum y ius in bello, esbozada por Vitoria, claramente formulada por Kant, se ha consumado" (Haggenmacher, 1983: 611). En palabras de Schmitt (2002: 126): “el problema de la guerra justa es separado de la causa justa, quedando sujeto a categorías jurídico-formales".

Se suele subrayar que la base del ius in bello es el principio de la igualdad de los beligerantes, frente a la discriminación de los adversarios propia de la doctrina de la guerra justa. De ahí se deduce a veces, a mi juicio erróneamente, que el primero implica la limitación humanitaria de los conflictos armados, por el reconocimiento mutuo de los contendientes, mientras la segunda justifica el castigo sin límite contra el enemigo injusto ${ }^{45}$. Pero ya dijimos que el principio de igualdad formal de los participantes puede igualmente incitar a los beligerantes a combatirse sin restricción, en ausencia de límites morales, al tiempo que convalida la posición del más fuerte.

Podemos encontrar en Grocio una clara anticipación de los principios del ius in bello. Pese a que apela a la distinción entre guerras justas e injustas, parece llegar a la posición según la cual la justicia o injusticia de la guerra es irrelevante para la imposición y aplicación de las reglas que han de seguir los beligerantes. La guerra pública (entre poderes soberanos) tiene consecuencias legales que son válidas para ambas partes, con independencia de la justificación de la causa de cada uno (Cf. IBP, III, 4, 4). (El desarrollo de la idea de que la guerra puede ser justificada por cada parte lleva a esta conclusión). La bilateralidad de los efectos se establece en virtud de condiciones meramente formales (IBP III, 3, $11-12 ; 4,3 ; 6,21$ ), y son independientes de la justicia material (IBP III, 6, 2; $7,1,2)$. Además, escapan al principio de proporcionalidad. En cuanto a los neutrales, proclama el deber de no favorecer al agresor injusto, ni perjudicar al

${ }^{45}$ Quien más ha insistido en esta tesis es Schmitt: "La igualdad de los soberanos los convierte en partenaires de guerra con derechos idénticos y evita los métodos de la guerra de aniquilación" (2002: 128). "Así pues, se había conseguido efectivamente, al menos en cuanto a la guerra terrestre en suelo europeo, una acotación y limitación de la guerra. Este milagro había sido producido por la transformación de las guerras civiles religiosas de carácter internacional de los siglos XVI y XVII en "guerras en forma", es decir en guerras de Estados de acuerdo con el derecho europeo de gentes" (2002: 139).

Araucaria. Revista Iberoamericana de Filosofía, Política y Humanidades, año 16, n 32. Segundo semestre de 2014. Pp. 69-92. ISSN 1575-6823 e-ISSN 2340-2199 doi: 10.12795/araucaria.2014.i32.04 
beligerante justo; pero en caso de duda hay que comportarse igual con las dos partes (IBP III, 17, 3) ${ }^{46}$.

El recurso al derecho de gentes facilita la adaptación de la perspectiva del derecho, en principio ligada a la justicia de las normas, porque permite conductas que serían difíciles de justificar según los criterios estrictos del derecho natural. Por ejemplo, Grocio justifica las represalias por el derecho de gentes, ya que no podría justificar por el derecho natural que recaigan sobre personas inocentes de actos ilícitos cometidos por terceros ${ }^{47}$. Por otra parte, el derecho de gentes no es un conjunto homogéneo, sino un cajón de sastre de normas, una amalgama que el mismo Grocio trata de justificar individualmente, "como si fuera necesario indicar en cada caso las razones que hacen posible el acuerdo entre los pueblos" (Haggenmacher, 1983: 587).

En todo caso, se plantea la cuestión de cuáles son los límites que no deben traspasarse en la actividad bélica. La propia noción de guerra justa parece excluir implícitamente la crueldad innecesaria, la ausencia de proporcionalidad en el castigo, las medidas que van más allá de lo necesario para alcanzar el fin perseguido.

Por ejemplo, cuando Vitoria aborda la cuestión del castigo a los inocentes por los delitos de los culpables (nocentes), admite que se pueda dar muerte a inocentes, sin intención directa de hacerlo, cuando sea necesario para conseguir el fin de la guerra justa; atendiendo, eso sí, a que no se sigan de la guerra males mayores que los que pretende evitar (Vitoria, De iure belli, §37).

Por su parte, Grocio, aunque tiene claro que las leyes permiten a veces cosas contrarias a la justicia, pero no es correcto hacerlas (cf. IBP III, 10, 1, 1), parece debilitar las restricciones tradicionales. Muchos intérpretes piensan que uno de los defectos de su tratado sobre el derecho de guerra es que, pese al propósito declarado inicialmente de humanizar la guerra, en el libro III parece abandonarlo. El derecho de gentes parece autorizar la supresión de las restricciones: cabe matar o injuriar a cuantos se encuentran en territorio enemigo, incluso si no portan armas (IBP, III, 4, 6). Se puede matar a los prisioneros (III, 4, 11) o esclavizarlos, o corromper el agua (III, 6, 17).

Se han propuesto diferentes explicaciones para esta actitud del autor: ¿expone lo que es derecho de gentes consuetudinario, sin aprobarlo? ¿Trata de mostrar que es un conocedor de las realidades de la guerra, no un académico idealista? (Lauterpacht) ${ }^{48}$. En todo caso, vemos cómo domina en el conjunto del

${ }^{46}$ No obstante, puede decirse que la distinción entre guerras justas e injustas tiene efectos en algunos terrenos. Un tratado de alianza no es vinculante respecto a un Estado que lleva a cabo una guerra injusta; un Estado que hace la guerra a un enemigo en posición muy injusta tiene derecho a imponer la pena capital a los que hacen contrabando, etc. (Cf. Draper, 1990: 196. Véase IBP II, 22).

${ }^{47}$ IBP III, 2, 1: "Por el mero derecho natural nadie está obligado por las acciones de otro, sino el que hereda sus bienes".

${ }^{48}$ Draper (1990: 198): "Respecto a la influencia de Grocio, es una triste reflexión la de que en las últimas etapas de la guerra [de los Treinta Años, $J P$ ] se incrementó la crueldad a medida que iban 
tratado la adaptación realista a las prácticas propias de la guerra, la aceptación resignada de los límites de la sujeción de la guerra al derecho. Grocio no separa por completo el derecho de la justicia, pero la voluntad de realismo lleva a que el vínculo se haga muy tenue (Cf. Haggenmacher, 1983: 583).

Sin embargo, Grocio dedica algunos capítulos del libro III, del $11^{\circ}$ al $16^{\circ}$, a los "temperamenta belli". Propone introducir cierta moderación en las prácticas de la guerra, más allá de lo permitido por el derecho. "Incluso cuando la justicia no lo exige, es a menudo agradable a la divinidad la moderación, y un alma grande para perdonar" -escribe (IBP, III, 11, 7). Exhorta, en primer lugar, a respetar la vida de los inocentes, siempre que pueda hacerse sin poner en riesgo la seguridad de la vida de muchos, o la de los Estados. En particular, debe respetarse la vida de los niños y la de las mujeres (salvo que éstas hayan cometido ciertos crímenes, o usurpado el oficio de los hombres), así como la de aquellos cuyo género de vida es ajeno a las armas, como los clérigos, cultivadores de las ciencias y las artes beneficiosas para la Humanidad, los pastores o los comerciantes. Debe aceptarse la petición de indulgencia de quien pide cuartel, o quien se rinde sin condiciones. Incluso cuando esté justificada la represalia, eso no autoriza a hacer una carnicería, ni a matar a los rehenes inocentes.

También reclama moderación en la destrucción de bienes y tierras del enemigo, que no debe hacerse sin necesidad ni proporcionalidad. No está justificada la destrucción de cosas necesarias para la subsistencia, aunque sí la devastación y desolación cuando apremian al enemigo a una actitud de paz. Tampoco la de aquellos bienes sin valor para la guerra, como los templos o las obras de arte, las cosas sagradas o los sepulcros. Tomar cosas del enemigo en la guerra no excluye el deber de restituir lo que se toma, dejando aparte lo que exija la seguridad, o lo que se toma para reembolsar una deuda previa o resarcirse de los gastos de guerra.

Quien hace una guerra justa tiene el derecho de apropiarse de los enemigos hechos prisioneros, y de transferirlos a otros como esclavos; pero sólo a aquellos esclavos como castigo por ofensas personales. Sin embargo, no se puede matar a un esclavo inocente, ni castigarlo despiadadamente. Se les puede exigir trabajar con moderación, según su fuerza y constitución.

La moderación y humanidad son especialmente aconsejables con el conjunto de los habitantes de las naciones conquistadas, a quienes se debe permitir conservar su antigua religión, y en parte sus leyes y costumbres, un cierto grado de autogobierno. Son además políticamente útiles (IBP, III, 15).

Ahora bien, estas consideraciones tienen sólo un alcance prudencial. Grocio, consciente de la brutalidad de las guerras de su época y de la necesidad

siendo publicadas nuevas ediciones de este tratado, y cuando su reputación como jurista llegó más alto que nunca".

Araucaria. Revista Iberoamericana de Filosofía, Política y Humanidades, año 16, $\mathrm{n}^{\circ} 32$. Segundo semestre de 2014 Pp. 69-92. ISSN 1575-6823 e-ISSN 2340-2199 doi: 10.12795/araucaria.2014.i32.04 
de mitigar su dureza, apela a la conciencia moral y religiosa de los beligerantes -"Debemos observar que las reglas de la caridad van más allá que las del derecho" (IBP, III, 13, 4) - o, si no estiman la virtud por sí misma, a la utilidad de la moderación (IBP, III, 12, 8). Pero al situar estas reflexiones fuera de la capacidad reguladora de las normas jurídicas, parece confiar en último término la moderación en la guerra al cálculo instrumental de las partes.

Cabe preguntarse, para concluir, si es posible la conciliación entre el discurso normativo -jurídico, pero en último término fundado en principios morales y religiosos-, y el reconocimiento de la lógica conflictiva de la política, que la guerra pone al descubierto de forma descarnada. Este parece ser el intento de Grocio, fallido según muchos intérpretes. Así piensa, por ejemplo, Zarka (1998: 180): "Sin retornar a la impotencia del discurso moralizador, la juridificación de la Guerra parece indicar de qué manera deberían hacer la guerra los hombres más que el modo en que la hacen. La lógica de la guerra no es en absoluto jurídica: se asienta en relaciones de potencia que son totalmente ajenas al derecho". Sin embargo, en la medida en que la política no renuncie a ordenar la vida social conforme a una aspiración de justicia, y a establecer fronteras a lo intolerable, pretendiendo a la vez reconocer el peso de la necesidad y el conflicto en la política, será difícil prescindir de ensayos de conjugación como el de Grocio. 


\section{Referencias bibliográficas}

\section{Fuentes}

Hugo Grotius: Commentary on the law of prize and booty (Versión inglesa de De iure praedae commentarius, ¿1605?). Ed. by Martina Julie van Ittersum. Indianápolis, Liberty Fund, 2006.

Hugo Grotius: De iure belli ac pacis libri tres ([1625] 1993) Aalen, Scientia. (Reimpresión fotomecánica de la edición de Leiden, 1939).

Hugo Grotius: The Rights of War and Peace (2005) Ed. by Richard Tuck. Indianápolis, Liberty Fund.

Hugo Grocio: Del derecho de presa. Del derecho de la guerra y de la paz. Textos de las obras "De Iure Praedae" y "De Iure Belli ac Pacis (1987): Traducción, introducción y notas de Primitivo Mariño. Madrid, Centro de Estudios Constitucionales.

Rousseau, J. J.: Emilio, o De la educación (1990): Traducción de M. Armiño. Madrid, Alianza.

Francisco de Vitoria: Sobre el poder civil. Sobre los indios. Sobre el derecho de guerra ([1528-1539] 1998): Estudio preliminar, traducción y notas de Luis Frayle Delgado. Madrid.

Vattel, Emmeric (1758): Le droit des gens. Londres (2 vols.).

\section{Bibliografía secundaria}

Bull, Hedley (1990): The Importance of Grotius in the Study of International Relations, en Bull, Kingsbury y Roberts, eds., pp. 64-93.

Bull, Hedley (2005): La sociedad anárquica. Madrid, Los Libros de la Catarata. Bull, Hedley, Benedict Kingsbury and Adam Roberts (1990): Hugo Grotius and International Relations. Oxford, Clarendon Press.

Cavallar, Georg (2002): The Rights of Strangers. Theories of International Hospitality, the Global Community and Political Justice since Vitoria. Vermont, Ashgate.

Cavallar, Georg (2011): Imperfect Cosmopolis. Studies in the History or International Legal Theory and Cosmopolitan Ideas. Cardiff, University of Wales Press. Donelan, Michael (1983): Grotius and the Image of War. Millennium: Journal of International Studies, vol. 12, no 3, pp. 233-243.

Draper, G. I. A. D. (1990): Grotius' Place in the Development of Legal Ideas about War en Bull, Kingsbury y Roberts, eds., pp. 177-207.

Haakonsen, Knud (1985): Hugo Grotius and the History of Political Thought. Political Theory, vol. 13, no 2, pp. 239-265.

Haggenmacher, Peter(1983): Grotius et la doctrine de la guerre juste. París, Presses Universitaires de France. 
Kolb, Robert (1997). Sur l'origine du couple terminologique ius ad bellum/ ius in bello. Revue internationale de la Croix-Rouge, 827. (Disponible en http://www. icrc.org/fre/resources/documents/misc/5fzh8x.htm).

Lauterpacht, H. (1946): The Grotian Tradition in International Law. The British Yearbook of International Law, 23, pp. 1-53.

Nabulsi, Karma (1999): An ideology of war, not peace: ius in bello and the Grotian tradition of war. Journal of Political Ideologies, 4 (I), pp. 13-37).

Schmitt, Carl (2002): El Nomos de la Tierra en el Derecho de Gentes del "Ius publicum europeum”. Granada, Comares.

Straumann, Benjamin (2006): The Right of Punish as Just Cause of War in Hugo Grotius' Natural Law, 2, www.historyofethics.org, 1-21.

Tuck, Richard (1993): Philosophy and Government, 1572-1651. Cambridge, Cambridge University Press.

Tuck, Richard (1999): The Rights of War and Peace. Political Thought and the International Order from Grotius to Kant. Oxford, Oxford University Press.

Van Ittersum, Martine Julia (2006): Profit and Principle. Hugo Grotius, Natural Rights Theories and the Rise of Dutch Power in the East Indies (1595-1615). Leiden, Brill.

Vincent, R. J. (1990): Grotius, Human Rights and Intervention en Bull, Kingsbury y Roberts, eds., pp. 241-256.

Zarka, Yves-Charles (1998): Philosophie et politique à l'âge classique. París, P. U. F. 